\title{
KANDINSKY E O ESPÍRITO. EMPO, LIBERDADE E VIDA NA CONCEPÇÃO KANDINSKYANA DA «VIBRAÇÃO INTERIOR»*
}

José Miranda Justo

(Universidade de Lisboa)

\begin{abstract}
«É melhor tomar a morte pela vida do que a vida pela morte. Ainda que uma única vez. E só num lugar tornado livre pode voltar a crescer algo. Aquele que é livre procura enriquecer-se por meio de todas as coisas e deixar que a vida de cada ente aja sobre $\mathrm{si}$ - mesmo quando se trate apenas de um fósforo queimado.»
\end{abstract}

Kandinsky, «Sobre a questão da forma», BR, 182.11

Estranha alternativa, esta: «tomar a morte pela vida» ou tomar «a vida pela morte». Alternativa entre dois enganos, entre duas ilusões. Como optar entre dois enganos? Como escolher, quando sabemos que a escolha é entre ilusão e ilusão?

«Ainda que uma única vez»? «Uma única vez» o quê? Uma única vez o engano? O engano que é «melhor» do que o outro engano? Ou uma única vez a escolha, a escolha que não é escolha? Ou «uma única vez»... tudo? A escolha, o engano, a morte e a vida, tudo, «ainda que uma única vez», em vez de vez nenhuma? Ou em vez de muitas vezes?

\footnotetext{
* Uma versão reduzida e muito simplificada da presente comunicação - com o título de «Kandinsky e o Espírito. Três deambulações a propósito de um "fósforo queimado"»foi preparada para ser publicada no "programa de sala» da apresentação de $O$ som amarelo, de W. Kandinsky, no C.C.B. em Fevereiro de 2003, com encenação de Anabela Mendes.

${ }^{1}$ As citações são identificadas com as siglas BR (Der Blaue Reiter) e GidK (Über das Geistige in der Kunst). As edições usadas e às quais se referem os números de página indicados são as seguintes: W. Kandinsky, F. Marc (orgs.), Der Blaue Reiter, Dokumentarische Neuausgabe (publ. por Klaus Lankheit), Piper, Munique 1984; W. Kandinsky, Über das Geistige in der Kunst, Benteli, Berna s.d.
}

Philosophica, 36, Lisboa, 2010, pp. 67-83 
«E só num lugar tornado livre...» Porquê «e»? Tornar um lugar livre é limpá-lo de tudo o que nele possa haver. Tornar um lugar livre é aniquilar a existência. É a morte, portanto. «E só...» Será isto o modo de dizer: «a morte, aliás, é necessária ao crescimento livre»? Ou será que o lugar se torna «livre» quando acontece a escolha impossível, aquela que escolhe «tomar a morte pela vida»? Mas como pode uma escolha ilusória «tornar livre» um lugar?

E depois..., a «vida» de... «um fósforo queimado»? Que «agir» se poderá esperar de um «fósforo queimado»? De uma «vida» que afinal não é vida? Que importância poderá ter o «agir» de um «fósforo queimado», se aquilo de que se fala é do «enriquecimento por meio de todas as coisas»?

Estas interrogações - aqui introduzidas em registo deliberadamente mais dramático do que vulgarmente possa ser julgado conveniente para a serenidade kandinskiana - hão-de encontrar, como facilmente se adivinha, resposta dentro da lógica interna do pensamento de Wassily Kandinsky. Mapeando de algum modo o trajecto que se segue, poderemos desde já distinguir três grandes motivos (num sentido mais musical do que literário), motivos que Kandinsky desenvolve repetidamente, com recurso a diferentes instrumentos, por vezes só parcialmente, outras como eco, outras ainda como tema principal da sua composição discursiva: o motivo da vida, o da liberdade e o do tempo. Reencontrá-los-emos, pois, várias vezes ao longo deste nosso percurso.

1. O horizonte do pensar kandinskiano é o «espírito», o «Geist». É para aí que tudo se dirige, é aí que tudo conflui ou... deveria confluir. É do «Geist», portanto, que deviam vir as respostas. Mas o «Geist» não fala. Pelo menos não fala nada que se pareça com a linguagem geral, logocêntrica, racionalizada. Se dissesse alguma coisa, o «Geist» diria «vibrações». Mas nem é o «Geist» que vibra. O que vibra é a «alma». A «alma» vibra de uma «vibração interior», de um som («Klang») que não é som («Laut»). (Chega mesmo a suspeitar-se que «alma» não seja outra coisa senão o nome do órgão da «vibração interior», da sede do «acorde íntimo».)

$\mathrm{O}$ «Geist» não é uma entidade. $\mathrm{O}$ «Geist» é simplesmente «das Geistige» («o espiritual»), ou seja, é uma qualidade. A qualidade abstracta da experiência artística: da apreensão na arte; da expressão artística; dos objectos (sejam eles quais forem) quando apreendidos enquanto vibração interior; da manifestação materializada da vibração interior. Ao «Geist» chega-se por uma atenção, por uma escuta. Uma atenção especial, preparada pela máxima desatenção a tudo o mais. Uma «maturação» $(B R, 161)$ que envolve uma espécie de desaprendizagem do geral, da «finalidade prática», e que portanto é uma «maturação» ao contrário, para a qual 
Kandinsky usa a analogia da vida infantil, em particular do desenho infantil $(B R, 168)$.

Com figuração ou sem ela, com referente ou sem ele, pela via «realista» ou pela via «abstraccionista» $(B R, 147-156)$, é sempre a uma «vibração sem objecto» («gegenstandslose Vibration»: GidK, 46) que se haveria de chegar. Na literatura, na música, nas artes plásticas (GidK, 43 e sgs.), nas «composições para palco» (GidK, 125 e sgs.; BR, 189 e sgs.), mas também na totalidade da «intuição» do «mundo», como havemos de ver no final destas considerações.

2. No final de Sobre o espiritual na arte, Kandinsky estabelece a articulação entre três categorias dos seus trabalhos plásticos: «Impressões» ${ }^{2}$, «Improvisações» e «Composições» (GidK, 142). Poderia parecer uma tipologia dos objectos artísticos. Mas não. Trata-se sobretudo da diferenciação de três modos da «construção» plástica.

As «Impressões» («Impressionen») são «expressão» desenhística ou pictórica de uma «impressão directa» («direkter Eindruck») da «natureza exterior».

As «Improvisações» («Improvisationen») são «expressão» preferencialmente «inconsciente» e «súbita» de «impressões da natureza interior».

As «Composições» («Kompositionen») são «expressão» intencional, racional, consciente, especialmente lenta («ganz besonders langsam»), de impressões interiores.

A diferença entre «Impressões» e «Improvisações» não é, portanto, análoga à diferença entre «Improvisações» e «Composições». As «Impressões» distinguem-se das «Improvisações» quanto à exterioridade ou interioridade da impressão que está na origem da expressão. Esta distinção, porém, não se aplica à diferença entre «Improvisações» e «Composições», pois que ambas dão expressão a impressões interiores. As «Improvisações» distinguem-se das «Composições» quanto ao carácter inconsciente (ou quase inconsciente) de umas e consciente das outras, quanto à instantaneidade (ou quase instantaneidade) das primeiras por oposição à elaboração lenta das segundas.

As «Composições», contudo, diz Kandinsky, são elaboradas «a partir dos primeiros esboços», ou seja, a partir de «Impressões» e de «Improvisações». Sendo assim, para que se mantenha a ideia de que as «Composições» dão expressão a um plano de interioridade, é preciso entender que as «Impressões», quando tomadas como material para as

2 Uso maiúsculas para estas categorias apenas para poder distinguir entre «Impressões» («Impressionen») - precisamente no sentido categorial introduzido por Kandinsky - e «impressão» («Eindruck») - no sentido «psicológico»: efeito de uma afecção (externa ou interna). 
«Composições», procederam já àquilo a que poderíamos chamar uma metamorfose da «impressão directa» da «natureza exterior» em «impressão interior».

O processo lento e intencional da «Composição» não exclui de modo algum o carácter inconsciente e imediato das «Improvisações» nem o carácter externo das «Impressões». Pelo contrário, a «Composição» constitui-se a partir desses dois planos, articulando-os, combinando ou cruzando os dados de cada um deles, intencionalmente, ou seja, em intenção de uma certa «obra». (E acontece que isto diz respeito às «Composições» pictóricas tanto quanto a outras, designadamente as «Composições para palco».)

Quando se chega ao plano da «composição» é da intencionalidade específica da arte que se trata. É esta intencionalidade que é preciso distinguir da intencionalidade instrumental e geral. Uma vez obtida essa distinção ver-se-á que a intencionalidade artística é liberdade. Poder-se-á então porventura encontrar um princípio de resposta para algumas das questões que nos assaltaram acima... Poder-se-á talvez entender que «aquele que é livre» possa «enriquecer-se» por meio de «um fósforo queimado»...

3. Recordemos então os momentos essenciais de uma notável sequência de «exemplos» oferecida por Kandinsky em «Sobre a questão da forma» (BR, 157 e sgs.).

Tais «exemplos» deverão, no dizer de Kandinsky, permitir sair «do domínio da reflexão para o domínio do captável/apreensível [«des Greifbaren»]». A expressão aqui usada parece desde logo significativa uma vez que sugere uma certa impossibilidade de «captar» convenientemente o problema em causa - a «questão da forma» - no plano da estrita reflexão (entenda-se: reflexão estética, teoria estética...). Assim sendo, o esforço reflexivo, não deixando de ter um lugar próprio, como obviamente se demonstra pela simples existência dos próprios escritos reflexivos kandinskyanos, é no entanto relegado para o lugar secundário, o lugar derivado, que costuma ser o dos exemplos face às teorias gerais. Exemplos e reflexão teórica surgem então invertidos na sua posição relativa. Os «exemplos» estão mais próximos da prática artística, quando não são simplesmente exemplos do próprio campo da arte $^{3}$, e a função da reflexão

${ }^{3}$ Exemplos do campo da arte são muito abundantes nos textos de Kandinsky; cf., por exemplo, no próprio texto «Sobre a questão da forma», o recurso a Henri Rousseau (BR, 172 e sg.), Picasso (173, 180), Lydia Wieber (169), Matisse (179 e sg.), Franz Marc (180), Le Fauconnier (180), etc. Em grande medida a primeira parte de Sobre o espiritual na arte, por exemplo, constrói-se em comentário a exemplos concretos da literatura, da música, da pintura. Em todo o caso parece possível distinguir com clareza entre esse tipo de exemplificação e os «exemplos» a que agora nos referi- 
afigura-se predominantemente prospectiva (colocação das «questões»), porventura didáctica, certamente negativa, crítica, no sentido em que pela reflexão se pode proceder ao exame de tudo aquilo que significa limitação impositiva, académica, normativa, do livre curso da necessidade artística $^{4}$. A reflexão estética kandinskyana decorre fundamentalmente da experiência artística - neste sentido chamar-lhe-íamos um empirismo estético - e desemboca inevitavelmente na prática artística - neste sentido diríamos que se trata de um pragmatismo estético.

Pois bem. A sequência de «exemplos» do texto «Sobre a questão da forma» tem por objectivo uma certa «captação». Nada mais nada menos do que a «captação» (apreensão sensível) do que seja, em situações diversas, a presença do «espiritual». Se ainda estivéssemos no plano da «reflexão» diríamos então que se tratava de algo como uma metodologia de encaminhamento para o «Geist». Mas como de facto estamos no plano dos «exemplos» não cabe falar de metodologia e teremos que pensar o encaminhamento como uma heurística do «Geist», um conjunto de exercícios de uma ginástica da percepção (exterior e interior), aos quais não ficaria mal a designação de «exercícios espirituais». Esta heurística tem, pois, em vista aquela maturação-desaprendizagem de que falávamos acima, enquanto «libertação» para a experiência artística espiritual (ou para o espiritual na experiência artística, o que é o mesmo). Ora, se assim é, então poderíamos pensar depois até que ponto aquilo que se passa no plano da «expressão» artística - designadamente no patamar mais elevado, que é o das «Composições» - poderá ser visto numa homologia inversa relativamente a esta heurística do «Geist». Deixaremos contudo essa reflexão para uma outra circunstância.

3.1. Vejamos então o primeiro momento da sequência de «exemplos». Kandinsky convida o «leitor» a isolar uma «letra» do texto que tem perante si e a «intuí-la» («anschauen») «com olhos inabituais», «apenas enquanto coisa» («erst als Ding»). O que assim se obtém - num primeiro passo que põe de lado a função «prática» da «forma abstracta que é de-

mos, que têm uma função mais operativa, constituindo de facto «exercícios» de preparação para a «espiritualidade» da experiência artística.

4 É notável a extensão dedicada nos escritos «reflexivos» de Kandinsky à crítica do academismo normativista. Em «Sobre o problema da forma», por exemplo, surge repetidamente a imagem de uma «mão negra», mortal, destruidora, negativa (cf., p. ex. $\left.{ }^{\circ}, B R, 136\right)$, que simboliza toda a limitação imposta à «espiritualidade»; em «Sobre a composição para palco», mais de metade do texto cumpre uma função de reflexão crítica sobre as inconsequências wagnerianas e outras; em Sobre o espiritual na arte, são muitas as páginas dedicadas à crítica da «crítica de arte». Quanto à aparente contradição do livre curso da necessidade artística veja-se o penúltimo capítulo da secção B de Sobre o espiritual na arte (127-128). 
signação permanente de um determinado som» - é uma «forma corpórea, que de um modo totalmente independente produz uma definida impressão exterior e interior».

Ora, diz Kandinsky, nesta perspectiva a «letra» passa a consistir em duas coisas: 1. uma «forma principal» inteiramente coincidente com o «fenómeno global» («= Gesamterscheinung»); 2. «diferentes linhas», desenhadas de maneiras diversas e combinadas nesse «fenómeno global». A «forma principal» pode surgir como «divertida», «triste», etc., ou seja, pode provocar «uma determinada impressão interior». O mesmo sucede com cada uma das «diferentes linhas» que se combinam na «forma principal».

Temos assim duas distinções iniciais, sendo que a segunda depende obviamente da primeira.

Vejamos a primeira distinção. Tudo neste exercício depende do «olhar inabitual». O que o «olhar inabitual» deve pôr de lado é precisamente o... habitual, o hábito, a habituação. O que é o hábito? O hábito é a sempre repetida, sempre reencontrada finalidade instrumental de um objecto. Quando ao objecto se subtrair essa finalidade prática obter-se-á uma «coisa», «apenas enquanto coisa». A «coisa», neste sentido, é irrepetível. Repetível é a finalidade prática. Porquê? Porque a finalidade, sendo independente de cada situação concreta, é geral e «abstracta» (i.e., não-corpórea), e só o geral-abstracto é repetível. A coisa é - ou seja, «aparece» enquanto fenómeno («erscheint») -; a finalidade repete-se, e repetindo-se precisamente enquanto abstracção geral, repete-se como não-ser, enquanto redução do fenoménico.

Torna-se assim porventura claro que o primeiro momento do percurso abstractivo (no sentido da «pureza» da experiência artística, como veremos mais adiante) é... um concretismo: arrancar o fenómeno, enquanto fenómeno concreto (corpóreo), à repetibilidade própria da finalidade prática, mas imprópria do fenómeno. Parece então óbvio que a repetição faz desaparecer a vida concreta do fenómeno, ou seja, a repetição mata... A «letra», que de acordo com uma longuíssima tradição cristalizada nas línguas europeias é letra morta, é então para Kandinsky o exemplo ideal (ad contrario) de como um «olhar inabitual» pode captar a «coisa» enquanto «vida» ou, se se quiser dizer de outra maneira, transformar morte em vida: «Quando o leitor tiver sentido esses dois elementos da letra, nele gerar-se-á prontamente o sentimento que esta letra provoca enquanto ente com vida interior.» Compreendemos assim que o mesmo se pode passar com um «fósforo queimado». O «fósforo queimado» está morto do ponto de vista do olhar habitual e da finalidade prática; mas, na perspectiva gerada pelo «olhar inabitual», a morte (afinal aparente) pode «ser tomada por vida». A partir desse momento o «fósforo queimado» «age». Mas, claro está, age apenas sobre aquele que for sujeito do 
«olhar inabitual». E o agir não é de modo nenhum ilusório, uma vez que é captado sensivelmente, como acontecimento.

Assegurada esta primeira distinção, Kandinsky orienta-nos então para uma segunda: o «fenómeno global» (ou «total») surge em contraponto com as «linhas» (elementos) que nele se combinam. O texto prossegue: «Vemos [...] que a letra consiste em dois elementos, que contudo afinal exprimem uma [só] sonoridade [«einen Klang ausdrücken»]. As diferentes linhas do segundo elemento podem ser 'divertidas' e contudo a impressão global (elemento 1) pode resultar 'triste'.» Sendo essas linhas «partes orgânicas» do primeiro elemento, então a «impressão global» do «fenómeno global» é decidida não no plano de cada órgão, mas no plano conjunto do organismo. Esta «subordinação dos diferentes elementos a uma [só] sonoridade» é o que acontece nas composições musicais ou nas composições plásticas. Esse é o plano em que «se revelam as leis da construção» (158).

Quer isto dizer que a "construção», sendo um complexo orgânico, resulta de uma convergência de elementos, cuja «impressão» parcelar se subordina à «impressão global», de um modo que, sendo comandado por esse resultado do todo, obedece às «leis» do todo, que, contudo, não são certamente leis gerais - aplicáveis a outros todos de idêntica natureza mas precisamente as leis de uma dada construção, ou seja, o regime de subordinação das partes à «impressão» do todo nessa construção. Se as «leis» fossem gerais, elas seriam enunciáveis a priori: seriam instruções de uma estética normativa. Mas não. Se Kandinsky diz que elas «se revelam» na «impressão» do todo, é precisamente porque a ideia destas «leis» está na dependência lógica daquilo a que acima chamámos o empirismo estético kandinskyano: elas são discerníveis em cada objecto artístico $a$ posteriori, como regulação interna exclusiva desse objecto. Mas não são discerníveis como «leis» objectivas, no sentido em que fossem propriedade do objecto artístico independentemente da experiência subjectiva do objecto; «revelam-se» na «impressão», ou seja, são discerníveis na sua acção («viva») sobre o sujeito, coisa que, como já sabemos, só acontece mediante o «olhar inabitual» do sujeito. Assim, o alcance desta ideia de «leis» é duplo (e particularmente significativo): (a) o objecto artístico, no plano das «leis de construção», só existe como tal na dependência de uma intencionalidade subjectiva - do espectador e do $\operatorname{artista~}^{5}$ - que opera a «revelação» das «leis»; (b) a «revelação» opera-se (para o sujeito, na «impressão» que ele experimenta) como vida, como acção, como singularidade activa, ou seja, não numa espécie de iluminação pontual, momentânea, mas numa duração para a qual se poderiam antes usar metáforas como a da cintilação, a da pulsação ou (precisamente) a da vibração.

5 Sobre a simetria «emissor» («artista»)-«receptor» («espectador») veja-se designadamente $B R, 146$. 
De momento, contudo, Kandinsky só pretende sublinhar que a «letra» tem uma dada eficácia, «age» («wirkt»), e age de duas maneiras: 1. age «enquanto sinal com uma [certa] finalidade»; 2. «age primeiro enquanto forma e depois enquanto sonoridade interior, autónoma e perfeitamente independente dessa forma» (158). É importante para os fins em vista, sublinha Kandinsky, compreender que estas duas acções (ou efeitos) não mantêm entre si uma relação de dependência mútua, e que «a primeira é exterior», enquanto que a segunda tem um sentido interior» («Es ist uns wichtig, daß diese zwei Wirkungen in keinem gegenseitigen Zusammenhange sind, und während die erste Wirkung eine äußere ist, hat die zweite einen inneren Sinn»; 158-159). A conclusão a tirar desta primeira secção da sequência exemplificativa é que «o efeito exterior pode ser diverso do interior, que é causado pela sonoridade interior». E Kandinsky acrescenta que este facto «é um dos mais poderosos e mais profundos meios de expressão em qualquer composição».

Este final do primeiro «exemplo» contém pelo menos dois momentos problemáticos. Por um lado, importa saber qual a razão de ser da distinção temporal introduzida a propósito do segundo efeito: «age primeiro enquanto forma e depois enquanto sonoridade interior». Por outro lado, interessa compreender como é que o "efeito interior» «é causado pela sonoridade interior».

Posta de lado a função sinalética da «letra», orientada para uma dada finalidade prática (acção 1), a acção 2 surge afinal como uma sequência de duas acções: «primeiro», acção da «letra» «enquanto forma» (chamemos-lhe acção 2-1); «depois», acção da «letra» «enquanto sonoridade interior autónoma e perfeitamente independente dessa forma» (chamemos-lhe acção 2-2). Ora, se na acção 2-2 a «sonoridade interior» é «autónoma»e «independente» da «forma» da acção $2-1$, então somos indubitavelmente obrigados a excluir a possibilidade de haver uma relação de tipo propriamente causal entre a acção 2-1 e a acção 2-2. Ficamos portanto na situação de termos uma relação de sequência temporal - antes-depois - que não é uma relação lógica de antecedente e consequente, mas que é inegavelmente importante, já que parece óbvio que só depois de 2-1 pode acontecer 2-2. Digamos, então, que a relação da acção 2-1 com a acção 2-2 terá que ser entendida por analogia com relações de possibilitação que não envolvam qualquer implicação lógica: propiciação, facilitação, talvez desencadeamento (no sentido mais etimológico), libertação (porventura como aquela libertação do «terreno» para que «possa voltar a crescer algo», como se dizia na citação de que partimos no início destas considerações)...

Propiciação? Poder-se-á falar da «perfeita» independência daquilo que é propiciado relativamente ao que o propicia? É útil notar que Kandinsky se refere de maneira diferente à ausência de relação entre a acção 1 e a acção 2, e à relação de independência «perfeita» entre as acções 2-1 
e 2-2. A não-relação entre 1 e 2 é referida, como vimos, na indicação de que «estas duas acções não mantêm entre si qualquer dependência mútua» («daß diese zwei Wirkungen in keinem gegenseitigen Zusammenhange sind»): por outras palavras, trata-se de uma situação de total arbitrariedade. O «olhar inabitual» pode concentrar-se na acção 2 exactamente porque nenhuma relação de motivação subiste entre 1 e 2 . Porém, ao falar da relação entre 2-1 e 2-2, Kandinsky diz que a «sonoridade interior» é $\left(1 .^{\circ}\right)$ «autónoma» («selbständig») e $\left(2 .^{\circ}\right)$ «perfeitamente independente» («volkommen unabhängig»). Parece evidente que os termos escolhidos, se forem compreendidos dentro da relação temporal («erst»-«später») em que se inscrevem, pressupõem precisamente a passagem da não-autonomia à «autonomia», da dependência à «independência». A relação entre 2-1 e 2-2 é então um devir-autónomo, uma independentização. Assim, a «forma» - e convém ter presente que tudo se orienta para a ideia de que «dizendo em termos abstractos, não há questão da forma em princípio» (162), ou seja, não importa «se o artista usa uma forma real ou abstracta», porque, «em termos abstractos», «ambas as formas são interiormente idênticas» (id.) -, a «forma», dizíamos, motiva a «sonoridade interior»; o que acontece é que a «sonoridade interior» se autonomiza a partir da «forma» (abstracta ou figurativa), tornando-se «perfeitamente independente». A «perfeição» desta independência é, evidentemente, uma superação da «forma» que só pode acontecer no plano da «interioridade»; a «forma», sendo exterior, nunca pode ser «perfeita», nem «perfeitamente independente». Podemos então entender a relação entre a «forma» e a «sonoridade interior» como uma incoatividade motivada, uma propiciação não causal mas proporcionante, na qual o destino da «forma» é a sua própria superação numa «perfeição» de ordem diferente, interior, não-motivada.

Entretanto a relação causal existe, mas existe noutro lado: a «sonoridade interior» causa a «impressão interior». Ora, como a «sonoridade interior» é exactamente o que se obtém com a acção 2-2, então, na continuidade da sequência 2-1 $\rightarrow 2-2$, teremos a sequência $2-2 \rightarrow 2-3$, sendo 2-3 igualmente uma acção, mas uma acção que precisamente estabelece a dita relação causal. Afinal, a acção 2 tem uma estrutura tripartida, mais complexa do que poderia parecer. A diferença fundamental entre as duas sequências parece passar por uma complexificação da própria concepção do tempo: o tempo da primeira sequência é distendido, é o tempo necessário à «autonomização» da "sonoridade interior»; o tempo da segunda sequência só pode ser um tempo ínfimo, uma quase-instantaneidade própria de uma causalidade toda ela interior e, portanto, sem vacilações, sem interferências, sem mediação. A concepção complexa do tempo que comanda o pensar kandinskyano envolve, pois, um tempo distendido, lento, sem causação, mas proporcionante da «libertação», e um tempo 
rápido em que a causação é imediata, rigorosa e total. Podemos ver o tempo lento na elaboração das «Composições» e o tempo rápido no modo como as «sonoridades interiores» despertadas (também lentamente) pela(s) «forma(s)» dessas «Composições» causam - agora instantaneamente - o «efeito interior», necessariamente diferente de indivíduo para indivíduo $^{6}$.

Voltando às nossas questões iniciais, será importante notar então que «vida» implica tempo e «morte» implica supressão total do tempo. Assim, «tomar a vida pela morte» é suprimir o tempo e, portanto, cortar pela raíz toda a possibilidade de experimentar a «sonoridade interior» na sua independência. Pelo contrário, «tomar a morte pela vida» é, por assim dizer, introduzir numa forma que subsiste apenas enquanto forma («morte») o tempo necessário para que dela se possa libertar a «sonoridade interior». Uma vez isolada essa «sonoridade interior», a «vida» pode «agir», ou seja, pode despertar imediatamente o «efeito interior»e, portanto, constituir «enriquecimento».

Resta, contudo, compreender em pormenor a causação imediata desse «efeito interior» pela «sonoridade interior». Porque, à primeira vista, poderíamos ser levados a pensar que «sonoridade interior» e «efeito interior» são a mesma coisa. Mas aí não haveria lugar para Kandinsky dizer explicitamente que «o efeito interior é causado pela sonoridade interior». Se a causação é explicitamente referida é porque ela envolve alguma distinção crucial. É o que procuraremos ver de seguida.

3.2. Examinemos então o segundo exemplo. Ainda na página impressa, o exemplo do travessão («Gedankenstrich»; 160 e sgs.). O travessão, «se for introduzido na colocação certa [...], é uma linha com uma significação prática orientada para fins.» Ao contrário do que se passava com o primeiro exemplo, Kandinsky procede agora de um modo aparentemente mais experimental, ou seja, submetendo o «travessão» a sucessivas modificações ou manipulações: prolongando-o, enquanto linha; introduzindo-o numa «colocação errada»; colocando-o numa página em branco (do livro); retirando-o, finalmente, do contexto livro e deslocando-o para um «meio» de natureza diferente, uma «tela». O que é notável nesta experimentação imaginária são as sucessivas tentativas de lateralizar, excluir, o domínio da intencionalidade prática, da finalidade («das Praktisch-Zweckmäßige»).

Examinemos apenas a parte final da experimentação: «Desloquemos então uma tal linha para um meio que consiga evitar perfeitamente o domínio da finalidade prática. Por exemplo, uma tela. Enquanto o especta-

6 Embora de maneira lateral, a inevitabilidade dessa diferença está enunciada em $B R$, 157. 
dor (agora já não é leitor) encarar a linha sobre a tela como um meio para a delimitação de um objecto, estará ainda sob a impressão da finalidade prática. Porém, no momento em que a si mesmo disser que o objecto prático no quadro quase sempre desempenha um papel meramente casual e não um papel puramente pictórico e que a linha por vezes tem exclusivamente uma significação puramente pictórica, nesse momento a alma do espectador está amadurecida para sentir a pura sonoridade interior dessa linha.» $(B R, 161$.

Se no primeiro exemplo tudo dependia do «olhar inabitual», agora tudo depende de um monólogo íntimo: «dizer a si mesmo». E qual é a estrutura central desse monólogo? Ela reside rigorosamente na oposição entre «quase sempre» («meistens») e «por vezes» («manchmal»); por outras palavras, entre o habitual e o excepcional. A função excepcional da linha, que é a de despertar uma «pura sonoridade interior», depende de um monólogo interior em que o «casual» ou «acidental» («zufällige Rolle») do objecto figurado é posto em contraste com o «papel» ou «significação» «puramente pictórica» («rein malerisch») dos factores presentes no quadro, designadamente as linhas. $O$ contraste não é entre a não-figuração e a figuração, mas entre o casual e o necessário, entre acaso e necessidade. A «linha», em pintura, pode ser pictoricamente casual (habitualmente) ou pictoricamente necessária (excepcionalmente). $\mathrm{O}$ que significa obviamente também que a distinção que importa não é entre finalidade e não-finalidade, mas entre finalidade instrumental (prática, diferida, segunda, externa, etc.) e finalidade pura (não-instrumental, imediata, primeira, interna, etc.). A finalidade instrumental é não-necessária, ou seja, tem o carácter arbitrário dos sinais convencionais. A finalidade pura é necessária, ou seja, tem o carácter motivado dos sinais naturais.

A «pureza» da «sonoridade interior» de que fala Kandinsky não é obviamente a «pureza» apriorística da metafísica, nem a do criticismo kantiano. É sobretudo uma metáfora que qualifica uma metáfora, e que, dessa maneira, procura cortar-lhe a raíz metafórica. É na introdução deste qualificativo - «pura» -, ou seja, na passagem da «sonoridade interior» à «pura sonoridade interior», que encontraremos a resposta para o problema da causação que deixámos enunciado acima.

Vejamos. Se se fala de uma «sonoridade interior», fala-se de sensibilidade interior, de uma afecção interior. Uma vez que, em Kandinsky, esta sensibilidade interior pode ser desencadeada pela via de qualquer um dos sentidos exteriores, é compreensível que num primeiro momento se recorra à ideia tradicional da audição como sentido médio (entre a visão e o tacto) e como campo preferencial da sinestesia ${ }^{7}$. Assim, todas as sensa-

${ }^{7}$ Apenas a título de exemplo, refira-se a teorização de J. G. Herder, no Cap. III da Parte I da Abhandlung über den Ursprung der Sprache (Ensaio sobre a origem da 
ções convergem na audição, todas elas têm um correspondente sonoro, despertam uma sonoridade. Mas, como é evidente, esta sonoridade já não é uma impressão sensível exclusivamente sonora. É uma sonoridade interior, ou seja, é o correspondente interior de qualquer impressão sensível, seja ela sonora, visual, táctil, etc. Deste ponto de vista, o termo «sonoridade» diz o mesmo que na velhíssima tradição das metáforas ópticas dizia o termo «imagem», mas com duas modificações essenciais: (a) por um lado, o termo diz também que a vibração interior é central em relação à esfera do sensível (e não hierarquicamente superior às outras impressões como acontecia com a «imagem» visual, que, por assim dizer, governava a concepção das restantes imagens) (cf. GidK, 66 e sgs.); (b) por outro lado, o termo diz também - e ainda por oposição à «imagem» visual - o carácter inefável, volátil, intraduzível, talvez sobretudo singular, da vibração interior (uma «imagem» visual descreve-se, as outras imagens não se descrevem tão bem e são portanto entendidas em regíme deficitário face à «imagem» visual; o «innerer Klang», pelo contrário, surge como aquilo que, de cada vez que acontece, é único, irrepetível, e portanto indescritível em linguagem geral). Recorrendo à linguagem das metáforas ópticas teríamos que usar uma formulação contraditória e dizer que a vibração interior seria uma luminosidade intensíssima maximamente obscura: máxima luminosidade experiencial, existencial, fenoménica, e mínima inteligibilidade geral.

Ora acontece que, se a metáfora auditiva tem estas vantagens, ela tem também a desvantagem de indicar preferencialmente um dos sentidos, como se a via das impressões (externas) auditivas fosse mais directa do que as restantes vias sensoriais. Sendo assim, Kandinsky usa a metáfora da «pureza» (ou «limpeza») para indicar a «sonoridade interior» na independência «perfeita» face à via particular pela qual a vibração seja, em cada caso, desencadeada. $\mathrm{O}$ «reiner innerer Klang» marca pois o corte entre o resultado de cada uma das afecções sensoriais (plano da «forma»), resultado que é vibração interior («sonoridade interior»), e o «efeito interior» («pura sonoridade interior»), que a vibração interior causa. As afecções sensoriais fazem vibrar a «alma» (ou mais rigorosamente até, na linguagem técnica da antiga psicologia racional, o «ânimo» - «Gemüt» $\left.{ }^{8}\right)$. Mas essa vibração pode não ser captada na pura interioridade. Isso é aliás o que acontece «a maior parte das vezes» - ou seja, em todas aquelas situações em que o espectador se queda pela «forma» ou pela intuição da «sonoridade interior». Para ser captada (excepcionalmente) como vibração «puramente interior», ela tem de ser objecto já não propriamente

\footnotetext{
linguagem), de 1772.

$8 \mathrm{Vd}$. em particular I. Kant, Anthropologie in pragmatischer Hinsicht (Antropologia em sentido pragmático), Parte I, § 24.
} 
daquela atenção outra que acima encontrámos sob a designação de «olhar inabitual», mas a juzante daquele monólogo interior que introduz precisamente uma separação entre o habitual e o excepcional, entre a continuidade de um «muitas vezes» («meistens») e a descontinuidade de um «às vezes» («manchamal»), ou seja, entre duas categorias do tempo que coincidem com a distinção dos tempos de que falávamos acima: o tempo distendido é um tempo no qual a continuidade do «meistens» está, digamos assim, em casa própria; o tempo quase-instantâneo da causação, pelo contrário, coincide em rigor com a descontinuidade daquilo que só acontece «manchmal».

Ora, quando a vibração é captada (excepcional e instantaneamente) como vibração puramente interior, o que se passa é exactamente aquilo que nos termos da antiga psicologia racional se chamava a afecção do «sentido interior» pelo próprio «ânimo»" ${ }^{9}$ ou, em termos mais próximos de Kandinsky, afecção da pura interioridade («espiritual») pelo sentimento da «sonoridade interior», sendo que uma tal afecção «causa» a «pura sonoridade interior». Dir-se-ia então que a vibração do "sentido interior» sinaliza sem mediação (ou seja, directa e naturalmente) o «espírito» («Geist»). $\mathrm{O}$ adjectivo «rein» marca assim a fundamental descontinuidade que é preciso introduzir entre a afecção (sensorial) e o "Geist». Continuidade (lenta) entre «forma» e «sentido interior»; descontinuidade (instantânea) entre «sentido interior» e «efeito interior» (ou «pura sonoridade interior»). Esta experiência da «pura sonoridade interior» é o «Geist», ou, dizendo melhor, é a presença do «espiritual» ao sujeito.

A presença do espiritual ao sujeito já não é a mera consciência do sujeito individual (essa ocorre no plano da «sonoridade interior», ainda não-pura). Na consciência reflexiva, a estrutura sujeito-objecto mantém-se intacta e, por assim dizer, duplica-se: mantém-se a relação entre o sujeito e os objectos, sem a qual, aliás, não há diferenciação do sujeito; e é essa mesma relação que se duplica, como reflexividade, na medida em que o sujeito se toma a si mesmo por objecto. Pelo contrário, na «vibração sem objecto» - expressão usada por Kandinsky em Sobre o espiritual na arte e que parece estar mais perto de conceptualizar determinadamente o problema que agora nos ocupa - é precisamente de uma interioridade sem objecto que se trata. Porém, se não há objecto, se o objecto é superado na passagem da «sonoridade interior» à «pura sonoridade interior», parece evidente que o sujeito também deixa de ser sujeito e necessariamente deixa de ser mera consciência. O sujeito deixa de poder ver-se a si mesmo no espelho do objecto. E contudo compreendemos que a «vibração» da "pura sonoridade interior» está aí, existe, acontece, naquele acontecer súbito de que falávamos acima. Mais ainda: diremos que ela

9 I. Kant, ibid. 
existe num dado sujeito individual, porque sem o processo subjectivo que a ela conduz ela não chegaria a existir, mas somos forçados a compreender também que no instante do súbito acontecer dessa «vibração», a individualidade do sujeito e do próprio trajecto subjectivo se apaga, de tal modo que a vibração é tudo... Pois bem, se a «vibração sem objecto» apaga a individualidade e se ela é tudo, então não dispomos de outra maneira de a conceptualizar senão dizendo que é universal. Universal, não no sentido de um universal lógico, mas no rigoroso sentido de uma presença total da vibração à vibração. Coisa que, não o esqueçamos, só pode acontecer excepcionalmente, instantaneamente, coisa que poderá acontecer «uma única vez» (como se diz na citação de que partimos), mas que é «melhor» que aconteça, «ainda que uma única vez», do que vez nenhuma.

Falta-nos, no entanto clarificar um aspecto do problema. É que não é possível contornar a questão da singularidade deste universal a que fomos conduzidos na tentativa de compreender a «pureza» da «vibração sem objecto». Quando falamos de uma presença da vibração à vibração estaremos ainda a falar de alguma coisa que aceite o nome de fenómeno? E o que constitui a singularidade de um fenómeno?

Se nos mantivermos na linha de pensamento em que vínhamos, pode dizer-se que de facto a «espiritualidade» da vibração é fenómeno. É fenómeno na exacta medida em que tem uma causação e que essa causação acontece no sujeito. Contudo, poderá perguntar-se se ainda faz sentido chamar-lhe fenómeno a partir do momento em que dizemos que a vibração apaga o sujeito da experiência. Penso que sim, embora com algumas cautelas. Se pensarmos que quando falamos em fenómenos estamos, regra geral, a falar já não exactamente da espessura incompreensível do fenoménico enquanto tal, mas precisamente da redução fenomenológica ou seja, o fenómeno só existe na relação em que imediatamente o colocamos com (ao menos) a possibilidade de o inteligir por redução -, então não é impossível pensar que há fenómenos que, sem deixarem de ser colocados nessa estrutura fenómeno-intelecção, resistem contudo à redução e à inteligibilidade, tendendo a surgir-nos precisamente como irredutíveis, como singularíssimos, como pura espessura fenoménica. Neste sentido, a presença da vibração à vibração acolhe a designação de fenómeno, desde que lhe juntemos os adjectivos capazes de a excepcionalizar: puro fenómeno, fenómeno singular.

Voltemos ao adjectivo «rein». Ao mesmo tempo que o adjectivo assinala a descontinuidade de que falávamos - a descontinuidade que supera a estrutura sujeito-objecto -, «rein» assinala também precisamente a singularidade da pura "vibração», a singularidade de cada estado-acto de «espiritualidade». Ora isto significa assinalar uma dupla impossibilidade: a impossibilidade de falar desses estados em linguagem geral e a impos- 
sibilidade de cada um desses estados poder funcionar como um signo geral de afecções ou de representações. Neste sentido pode dizer-se que os estados «espirituais» não têm qualquer significado embora tenham, como é evidente, sentido. Cada estado da «espiritualidade» tem exactamente o sentido singular que lhe é próprio; é puro fenómeno, puro acontecer fenoménico, sem redução fenomenológica, pela simples razão de que foi obtido pela descontinuidade que o separa do fenoménico redutível que é o das afecções; é sinal (ou forma simbólica) na sua eficácia indicativa (ou mostrativa), mas é sinal exclusivamente de si mesmo, sem mediação entre sinalizante e sinalizado, pela simples razão de que foi obtido por introdução de uma descontinuidade que o separa das palavras gerais nas quais se processa a redução de todo o fenoménico. Ora, como é sabido, sem redução do fenoménico, designadamente na linguagem geral, não há utilização ou utilidade possível dos fenómenos, não há «finalidade prática», nem há «significação».

3.3. Diremos então, para terminar do modo mais amplo possível, que é precisamente um campo de formas simbólicas totalmente destituído de simbolização geral aquilo que os diferentes passos do modelo kandinskyano pretendem obter.

De facto, a sequência de «exemplos» do texto de Kandinsky «Sobre a questão da forma», contém ainda um terceiro momento: «Se o leitor prosseguir e intuir cada um dos objectos que porventura estejam em cima da sua mesa (ainda que seja apenas uma ponta de charuto), há-de notar de pronto as mesmas duas acções [ou efeitos]. Seja onde e quando for (na rua, na igreja, no céu, na água, no estábulo ou na floresta), em toda a parte se apresentarão as duas acções [ou efeitos], e em toda a parte a sonoridade interior será independente do sentido exterior.» (BR, 167-168.) Ou seja, aquilo que no segundo «exemplo» se conseguiu obter num plano que a partir de um dado momento - o momento do diálogo interior que faz a distinção entre «meistens» e «manchmal» - parecia ter que ser inevitavelmente o da arte, projecta-se de súbito sobre a totalidade da experiência. Como no início da sequência exemplificativa, mas agora com uma intencionalidade manifestamente outra. Na verdade é da «feitura»-em termos goodmanianos - ou da «construção» - em termos kandinskyanos - de um «mundo» outro que se trata aqui. Agora, ou seja, depois do tempo distendido que supera a «forma» e do tempo instantâneo em que se dá a passagem à pura interioridade, Kandinsky pode concluir assim: «O mundo soa [«klingt»]. Ele é um cosmos de entes agindo espiritualmente. É assim que a matéria morta é espírito vivo.» (168)

Um «cosmos»! É fácil compreender que este «cosmos» se contrapõe a um caos: o caos da disparidade e da prolixidade do «sentido exterior», ao serviço da errância das «finalidades práticas». Ora, se o «mundo» é 
«cosmos», se é um «cosmos» em oposição ao que «habitualmente» nos parece ser um cosmos e que afinal é um caos, é porque a «pura sonoridade interior» - é obviamente dessa que se fala quando se diz que «o mundo soa» («die Welt klingt») - tem um papel organizante. Mas esse papel organizante, que é necessariamente o de uma linguagem, não pode já ser visto em analogia com a imprecisão caótica da função organizativa da linguagem geral, a linguagem da redução fenomenológica. A organização, o organismo - ou a "construção», para usar o termo kandinskyano mais apropriado (cf. 181) - de um «mundo que soa» tem que ser pensada por via de uma outra analogia, como a própria terminologia kandinskyana sugere («klingt», «Klang»): a música.

Ora, é sabido que quando Kandinsky pensa na música, pensa antes de mais em Schönberg. E pensa na música de Arnold Schönberg como harmonia total, fora dos limites da «harmonia», digamos literalmente, pré-estabelecida, i.e. normativa, da tradição musical e da teoria da música associada a essa tradição (cf., por exemplo, GidK, 48-49). A música de Schönberg é, para Kandinsky, harmonização do (aparentemente) desarmónico, ou seja, daquilo que a linguagem da música, enquanto linguagem tradicional e portanto também convencional e geral, excluiu do seu campo de possibilidades. Por outras palavras, a música de Schönberg, no terreno que lhe é próprio - e que é o dos sons propriamente ditos -, oferece, em ponto pequeno, uma imagem do cosmos em ponto grande que é o de um «mundo» de «entes» todos eles vibráteis - se essa vibratilidade for devidamente propiciada, como vimos -, e todos eles fazendo então vibrar as cordas da «espiritualidade» (ou seja, causando a pura vibração interior). Escreve Kandinsky: «A música schönberguiana introduz-nos num novo império, em que as vivências musicais [já] não são acústicas, antes puramente anímicas [«rein seelische»]» (GidK, 49).

E porque assim é, não parece despropositado ver o modelo kandinskyano em que se articulam a «vida», a «liberdade» e o desdobramento crucial dos tempos, à luz do cepticismo face à linguagem geral - aquele cepticismo que ganha expressão nas últimas décadas do séc. XIX, com Nietzsche, Hofmannstahl, Fritz Mauthner e outros, e que se prolonga ainda pelas primeiras décadas do séc. XX -, mas, ao mesmo tempo, vê-lo como um modelo fortemente atravessado pela convicção de que a arte pode abrir o território de uma totalidade da experiência, vivida como plenitude do sentido interior. Ora acontece que, no preciso momento em que Kandinsky pensa assim, está a começar a configurar-se no pensamento de um seu contemporâneo, Ernst Cassirer, uma «filosofia das formas simbólicas» que procurará dar conta, entre outras coisas, da totalidade da experiência como um cosmos, no qual, a par do mito, da linguagem e da ciência, a arte desempenha um papel fundacional absolutamente incon- 
tornável na superação dos «moldes» estáticos e servis dentro dos quais o pensamento se limita a dar resposta às «finalidades práticas» que lhe são impostas. É sabido que a teorização de E. Cassirer - ao contrário do que decorre do modelo de Kandinsky - não prescinde da generalização envolvida nas «formas simbólicas», mas a reflexão cassireriana sobre a arte (e também sobre a linguagem) busca compreender designadamente o mesmo problema da singularidade que tão central parece ser no pensamento de Kandinsky.

E é por estas razões que faz sentido, a meu ver, pensar os objectivos de Kandinsky por via de uma aproximação diferenciada relativamente a Cassirer (sendo que a tónica recai inevitavelmente nessa diferenciação): um campo de «formas simbólicas», destituído, porém, de simbolização geral.

\begin{abstract}
On the basis of Kandinsky's article "On the Question of Form" (as well as passages of Concerning the Spiritual in Art), there arises the possibility of reconstructing the specific features of the artist's concept of "pure inner vibration" in connection with the concept of the "spiritual". These features include an important articulation of different modalities of time (hastiness, protracted time and suddenness), and a complex gradation of inner experience that starts with abstraction from external finality and ends with a criticism of subjectivity and a conception of inner universality, which - instead of being reducible to a logical procedure - indicates the exact place of singularity (and art) inside the structure of one's experience.
\end{abstract}

Keywords: Kandinsky, Inner Vibration, Time, Singularity 